\title{
Effect of Incarcerated HF on the Chemical Reactivity of Endo- hedral HF@C60
}

\author{
Sara Vidal, ${ }^{\mathrm{a}}$ Marta Izquierdo, ${ }^{\mathrm{a}}$ Shamim Alom, ${ }^{\mathrm{b}}$ Marc Garcia-Borràs, ${ }^{\mathrm{c}, \mathrm{d}}$ Salvatore Filippone, ${ }^{\mathrm{a}}$ Sílvia \\ Osuna, ${ }^{\mathrm{d}}$ Miquel Solà,${ }^{\mathrm{d} *}$ Richard J. Whitby ${ }^{\mathrm{b} *}$ and Nazario Martín ${ }^{\mathrm{a}, \mathrm{e} *}$ \\ ${ }^{a}$ Departamento de Química Orgánica, Facultad de Química, Universidad Complutense, Avda. Complutense s/n E-28040 Ma- \\ drid, Spain. ${ }^{b}$ Chemistry, University of Southampton, Southampton, SO17 1BJ, U.K. ${ }^{c}$ Department of Chemistry and Bioche- \\ mistry, University of California Los Angeles, 607 Charles E Young Drive East, CA90095 Los Angeles, USA. 'Institut de Quí- \\ mica Computacional i Catàlisi and Departament de Química, Universitat de Girona, c/ Maria Aurèlia Capmany 6, 17003 \\ Girona, Spain. ${ }^{e}$ IMDEA-Nanociencia, C/ Faraday, 9, Campus de Cantoblanco, E-28049 Madrid, Spain.
}

KEYWORDS: Endohedral fullerenes, cis-trans isomerization, H-bonding assistance, asymmetric catalysis.

\begin{abstract}
The first chemical modification on the endohedral $\mathrm{HF} @ \mathrm{C}_{60}$ is reported. In particular, the isomerization from optically pure $(2 S, 5 S)$-cis-pyrrolidinofullerene $\mathbf{2} \mathbf{b}$ to $(2 S, 5 R)$-trans-pyrrolidinofullerene $\mathbf{2} \mathbf{b}$ has been studied and compared with empty $\mathbf{C}_{60}(\mathbf{2} \mathbf{a})$ and endohedral $\mathrm{H}_{2} \mathrm{O} @ \mathrm{C}_{60}(3)$. Interestingly, the incarcerated $\mathrm{HF}$ molecule contributes to increase the isomerization rate through a $\mathrm{H}-$ bonding assistance involving weak hydrogen bonding without affecting the final cis-trans ratio or promoting the loss of enantioselective control through the retro-cycloaddition reaction. The comparative study shows a kinetic order for the isomerization process of $\mathrm{H}_{2} \mathrm{O} @ \mathrm{C}_{60}>\mathrm{HF} @ \mathrm{C}_{60}>\mathrm{C}_{60}$, thus confirming the effect of the incarcerated species on the zwitterionic intermediate stability.
\end{abstract}

Since the detection of endohedral fullerenes following the discovery of $\mathrm{C}_{60},{ }^{1}$ many species such as metals, noble gases, clusters, atoms or molecules, have been encapsulated in the hollow fullerene cage. The main method to achieve endohedral fullerenes is based on the arc discharge of graphite rods containing metals. However, controlling the size of the carbon cage or the product distribution by using this methodology is not possible. "Molecular surgery" emerged as an alternative and suitable methodology to synthesize endohedral fullerenes in a controlled manner, and paved the way toward atoms or small molecules encapsulation, namely $\mathrm{H}_{2} @ \mathrm{C}_{60},{ }^{2} \mathrm{He} @ \mathrm{C}_{60},{ }^{3}$ and $\mathrm{H}_{2} \mathrm{O} @ \mathrm{C}_{60}$ (Figure 1). ${ }^{4}$

Because of their size, diatomic guest molecules are ideal candidates to be encapsulated inside $\mathrm{C}_{60}$. Hydrogen fluoride (HF) is frequently used in a variety of organic synthetic protocols and has been extensively studied. ${ }^{5}$ HF molecules create hydrogen bonds between them forming aggregates; therefore, the study of isolated HF molecules is complicated. Recently, Krachmalnicoff et al., have successfully isolated the HF molecule inside $\mathrm{C}_{60}$ fullerene, thus forming the new endohedral HF@ $\mathrm{C}_{60}$ molecule. ${ }^{6}$ A single HF molecule trapped in a fullerene cage provides the opportunity to analyze its singular properties in an interaction free situation as well as in a well-defined environment. Furthermore, considering the polarity of the HF molecule, it is expected to have an impact on the exohedral reactivity of the [60]fullerene cage.

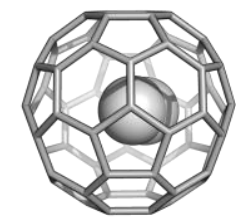

$\mathbf{H}_{2} @ \mathbf{C}_{60}$

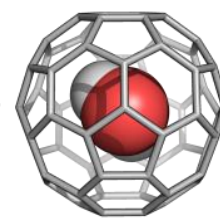

$\mathrm{H}_{2} \mathrm{O} @ \mathrm{C}_{60}$

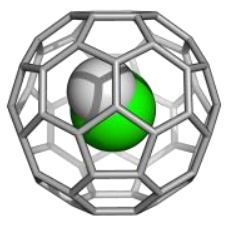

HF@C 60
FIGURE 1. Endohedral [60]fullerenes bearing a neutral molecule in the inner cavity synthesized by molecular surgery.

It is known that the encapsulated molecules in endofullerenes can affect the exohedral reactivity of the fullerenes carbon cage. ${ }^{7}$ Dolgonos et al. reported a computational study of several diatomic molecules encapsulated into $\mathrm{C}_{60} .{ }^{5 \mathrm{~b}}$ They surmised that the dipole moment of the polar guest molecules trapped inside $\mathrm{C}_{60}$ is decreased after the encapsulation, and specifically, the HF molecule exhibits the lowest interaction energy with the $\mathrm{C}_{60}$ compared with other polar molecules investigated. Some of us have demonstrated the interaction of polar molecules inside fullerenes by reporting the cis-trans isomerization of enantiomerically pure $\mathrm{H}_{2} \mathrm{O} @ \mathrm{C}_{60}$ pyrrolidines, showing the existence of a hydrogen bonding assistance between the carbanion on the cage and the trapped water molecule. $^{8}$

Herein, we report the first exohedral functionalization on the novel HF@ $\mathrm{C}_{60}$ using an efficient methodology to obtain enantiomerically enriched $\mathrm{HF} @ \mathrm{C}_{60}$ pyrrolidines. A comparative study between pristine $\mathrm{C}_{60}, \mathrm{H}_{2} \mathrm{O} @ \mathrm{C}_{60}$, and $\mathrm{HF} @ \mathrm{C}_{60}$ on the cistrans isomerization process is also discussed for a better understanding of the effect of the encapsulated molecule on the isomerization reaction. Furthermore, DFT calculations at the 
M06-2X/6-311++G(d,p)//OLYP/TZP level of theory nicely rationalize the experimental evidences.

\section{Results and discussion}

The synthesis of new enantiomerically enriched fulleropyrrolidines was carried out using the reported methodology involving a 1,3-dipolar cycloaddition of $N$-metalated azomethine ylide. ${ }^{9}$ In order to determine the difference in the chemical reactivity between empty $\mathrm{C}_{60}$ and $\mathrm{HF} @ \mathrm{C}_{60}$, the reaction was carried out with a mixture of both fullerenes in a ratio 12:88 $\left(\mathrm{C}_{60}: \mathrm{HF} @ \mathrm{C}_{60}\right)$ under the same reaction crude, thus ensuring the same experimental conditions.

Following Scheme 1, the mixture of fullerenes reacted with iminoester $\mathbf{1}$ in the presence of the corresponding metal salt / chiral ligand pair to yield each one of the four enantiomers of the respective fulleropyrrolidines, namely the cis-2a and cis2b and the trans-2a and trans-2b for the $\mathrm{C}_{60}$ and $\mathrm{HF} @ \mathrm{C}_{60}$, respectively, in good enantiomeric excesses.

Scheme 1. Synthesis of enantiomerically pure fulleropyrrolidines cis-2a,b and trans-2a,b.

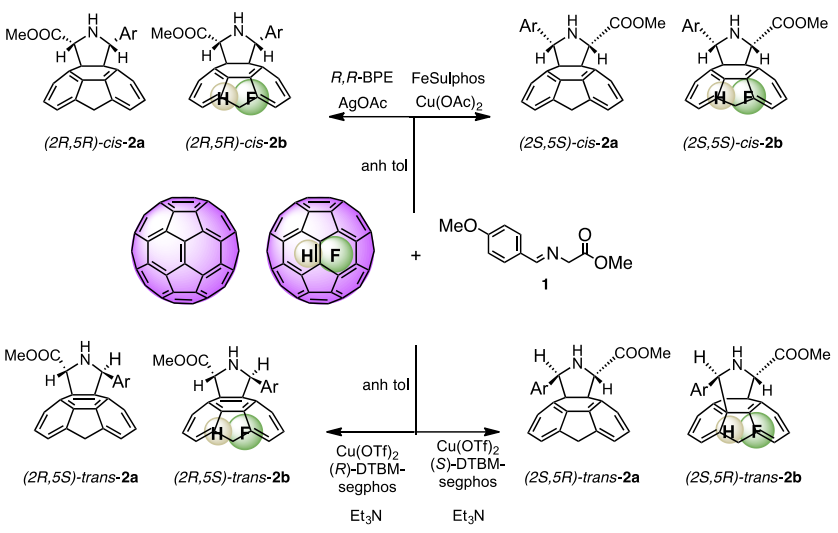

Interestingly, despite the polarity of the HF molecule, we did not observe significant differences in terms of reactivity on the carbon cage of the $\mathrm{HF} @ \mathrm{C}_{60}$ compared with $\mathrm{C}_{60}$. Indeed, the ratio of the pristine cages before and after reacting remained unaltered, $\left(\mathrm{C}_{60}: \mathrm{HF} @ \mathrm{C}_{60}=12: 88\right)$, as well as the ratio of pyrrolidine- $\mathrm{C}_{60}$ and pyrrolidine-HF@ $\mathrm{C}_{60}$. These experimental data, corroborated by theoretical calculations (see below) contradict a priori the expected higher reactivity for the $\mathrm{HF} @ \mathrm{C}_{60}$ molecules as a result of an acidic/electrophilic LUMO activation of the cage double bonds.

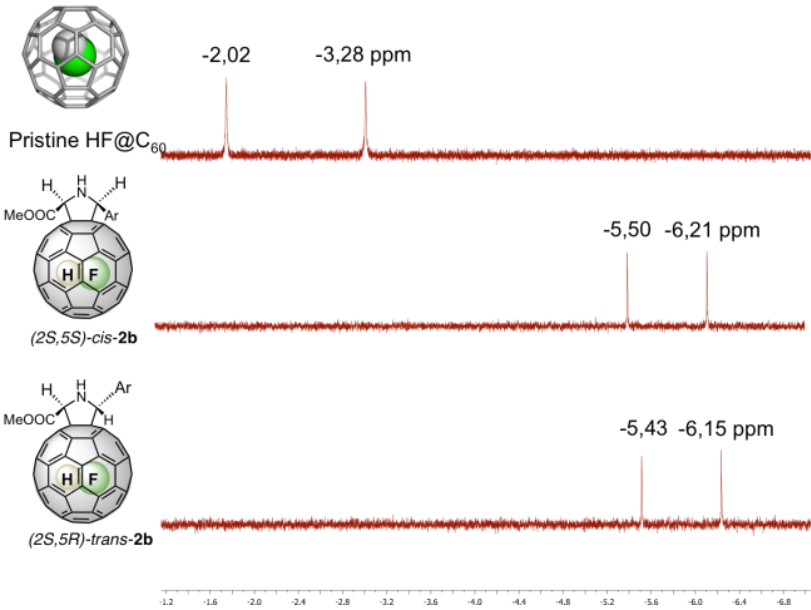

FIGURE 2. ${ }^{1} \mathrm{H}-\mathrm{NMR}\left(700 \mathrm{MHz}, \mathrm{CDCl}_{3}, 298 \mathrm{~K}\right)$ spectra $(-1,2$ to $-7 \mathrm{ppm}$ ) of compounds cis- and trans-2b and pristine $\mathrm{HF} @ \mathrm{C}_{60}$.

The four new enantiomers cis- and trans-2b were fully characterized by NMR spectroscopy and mass spectrometry (S.I.). The signal for the inner proton of pristine HF@ $\mathrm{C}_{60}$ in the ${ }^{1} \mathrm{H}$ NMR spectrum appears at $-2.65 \mathrm{ppm}(J=505.6 \mathrm{~Hz})$ as a doublet. However, if the carbon cage is functionalized that signal is shifted to $-5.81 \mathrm{ppm}(J=505.8 \mathrm{~Hz})$ for cis-2b and to -5.88 ppm $(J=506.0 \mathrm{~Hz})$ for trans-2b (Figure 2 and S.I.).

Enantiospecific cis/trans isomerization: Anchimeric assistance of the inner molecule.

In order to get a better understanding of the HF behavior inside the carbon cage, we moved our attention to the isomerization process that involves the exohedral [60]fullerene functionalization. In this regard, the easy availability of optically active derivatives enables the use of chiral information as a powerful tool to shed light into the mechanism involved. Thus, analogously to a previous related work reported by some of us, ${ }^{8}$ we now study the isomerization process from the optically pure $(2 S, 5 S)$-cis- to the $(2 S, 5 R)$-trans pyrrolidinofullerene that proceeds with absolute enantiospecificity. This process can be accounted for by a stepwise mechanism with a configuration inversion at the pyrrolidine $\mathrm{C} 5$ carbon atom while the configuration at $\mathrm{C} 2$ is maintained without losing enantiomeric excess. This enantiospecificity is coherent with the formation of a zwitterionic intermediate by heterolytic pyrrolidine ring opening between the $\mathrm{C} 5$ and the cage (see Figure 3 ) that gives rise to a stable benzylic cation and a negative charge on the cage. 


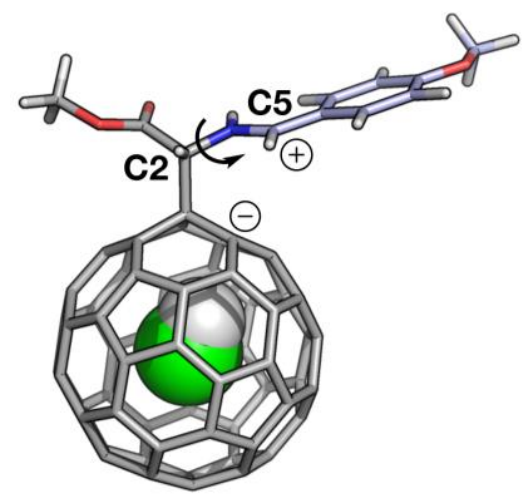

FIGURE 3. Zwitterionic intermediate formed by a carbanion on the $\mathrm{C}_{60}$ cage and a benzylic cation on the former pyrrolidine ring.

The carbanion of the zwitterionic intermediate can interact with the inner species and determine its stability. The negative charge in the carbon atom of the [60]fullerene cage is stabilized by the $\mathrm{H}$ atom of the inner $\mathrm{HF}$ molecule, thus making the process faster. In a second step, the $\mathrm{N}-\mathrm{C} 2$ bond of the intermediate rotates and is bonded back to the fullerene cage (Figure 3).

In addition to the study on the isomerization process from the optically pure $(2 S, 5 S)$-cis-pyrrolidinofullerene $\mathbf{2 b}$ to the (2S,5R)-trans-pyrrolidinofullerene $\mathbf{2} \mathbf{b}$, it has also been compared with those of the empty $\mathrm{C}_{60}$ (2a) and endohedral $\mathrm{H}_{2} \mathrm{O} @ \mathrm{C}_{60}(3)$ (Figure 4). Thus, we can explore the influence of the hydrogen bonding - generated by the carbanion on the fullerene sphere and the hydrogen of the inner molecule $\left(\mathrm{H}_{2} \mathrm{O}\right.$ and $\mathrm{HF}$ ) - on the racemization process. It is important to mention, however, that moderate temperatures have been used in order to avoid competitive cycles of retro-cyloaddition/cycloaddition reactions also leading to uncontrolled racemization processes. The selected system used for the isomerization experiment was the enantiomer $(2 S, 5 S)$-cis-fulleropyrrolidine for all the cases with a cis/trans ratio of $98 / 2$ for $\mathbf{2 a}$ and $\mathbf{3}$ and 96/4 for $\mathbf{2 b}$ (see SI). The experiments were performed in chlorobenzene/acetonitrile $1: 1$ as solvent mixture at three different temperatures $\left(25^{\circ} \mathrm{C}, 30^{\circ} \mathrm{C}\right.$, and $\left.40^{\circ} \mathrm{C}\right)$.

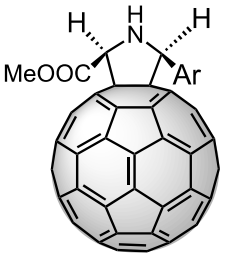

$(2 S, 5 S)-c i s-2 a$
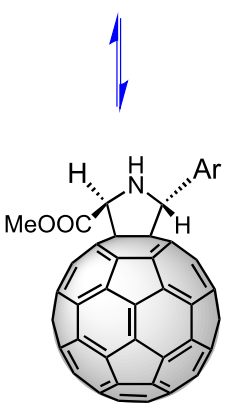

(2S,5R)-trans-2a

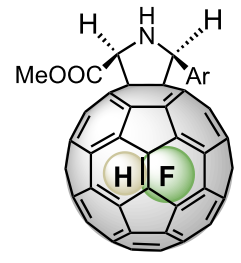

$(2 S, 5 S)-c i s-2 b$
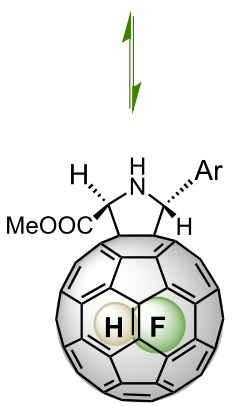

(2S,5R)-trans-2b

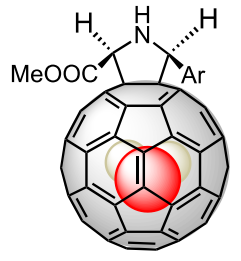

$(2 S, 5 S)-$ cis-3
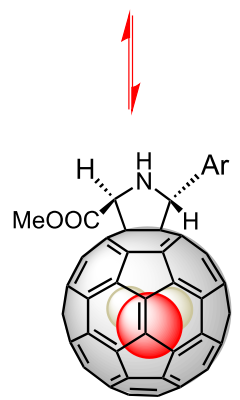

(2S,5R)-trans-3
FIGURE 4. Isomerization process from the optically pure $(2 S, 5 S)$-cis-pyrrolidino[60]fullerene to the $(2 S, 5 R)$-trans-pyrrolidino[60]fullerene.

The reactions were monitored by HPLC until the equilibrium stages were reached (see Figure XX in the S.I.). Integration of the peak areas was used to determine the relative amount of the isomers at any time during the isomerization. These equilibrium stages and the time needed to reach them were different for each system and are summarized in Table 1 . At $25^{\circ} \mathrm{C}$, the equilibrium stage was $77 / 23$ cis:trans while at $30^{\circ} \mathrm{C}$ and $40^{\circ} \mathrm{C}$, the equilibrium stage cis/trans ratio changed significantly toward 59/41 and 55/45, respectively. In all cases, the enantiomeric excesses of the trans derivatives remained unaltered demonstrating the enantiospecificity of the isomerization process (see SI).

The proposed mechanism for the isomerization (equilibrium reaction) follows a first-order rate law. However, competing reactions such as the previously reported retro-cycloaddition (retro-Prato) ${ }^{10}$ and the racemization are also involved. This process could be outlined according to the following scheme:

Scheme 2. Representation of the reactions involved in the isomerization process.

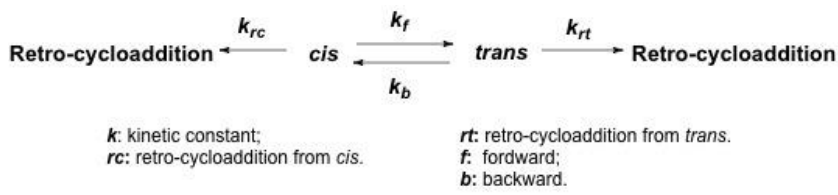

If we ignore the retro-cycloaddition reaction contribution, the reaction rate would remain:

$$
\begin{array}{ll}
\mathrm{V}=-\frac{d[c i s]}{d t}=k_{\mathrm{f}}[c i s]-k_{\mathrm{b}}[t r a n s] & \text { equation (1) } \\
\ln \frac{\left(x-x_{e}\right)}{\left(x_{0}-x_{e}\right)}=-\left(k_{\mathrm{f}}+k_{\mathrm{b}}\right) \mathrm{t} & \text { equation (2) } \\
K=k_{\mathrm{f}}+k_{\mathrm{b}} & \text { equation (3) }
\end{array}
$$


Where $x, x_{e}$, and $x_{o}$ are the concentrations of cis adduct at time $t$, at equilibrium, and at the starting point $(t=0)$, respectively, and $k_{\mathrm{f}}$ and $k_{\mathrm{b}}$ are the rate constants for the forward and backward cis-trans isomerization.

Table 1. Comparison of isomerization reaction rates of $(2 S$, $5 S)$-cis-2a, $(2 S, 5 S)$-cis-2b and $(2 S, 5 S)$-cis-3 in chlorobenzene:acetonitrile $1: 1$ at $25^{\circ} \mathrm{C}, 30^{\circ} \mathrm{C}$, and $40^{\circ} \mathrm{C}$.

\begin{tabular}{|c|c|c|c|}
\hline Compound & $\begin{array}{c}\mathbf{T} \\
\left.\mathbf{C}^{\mathbf{C}} \mathbf{C}\right)\end{array}$ & $\begin{array}{c}\text { cis/trans } \\
\mathbf{e q}\end{array}$ & $\boldsymbol{K}\left(\mathbf{h}^{\mathbf{- 1}}\right)$ \\
\hline $\mathbf{2 a}$ & 25 & $77 / 23$ & $5,29 \times 10^{-3} \pm 1,90 \times 10^{-4}$ \\
\hline $\mathbf{2 b}$ & 25 & $77 / 23$ & $9,03 \times 10^{-3} \pm 3,92 \times 10^{-4}$ \\
\hline $\mathbf{3}$ & 25 & $77 / 23$ & $10,95 \times 10^{-3} \pm 1,08 \times 10^{-3}$ \\
\hline $\mathbf{2 a}$ & 30 & $59 / 41$ & $8,50 \times 10^{-3} \pm 2,88 \times 10^{-4}$ \\
\hline $\mathbf{2 b}$ & 30 & $59 / 41$ & $10,26 \times 10^{-3} \pm 4,01 \times 10^{-4}$ \\
\hline $\mathbf{3}$ & 30 & $59 / 41$ & $12,90 \times 10^{-3} \pm 5,99 \times 10^{-4}$ \\
\hline $\mathbf{2 a}$ & 40 & $55 / 45$ & $11,80 \times 10^{-3} \pm 6,34 \times 10^{-4}$ \\
\hline $\mathbf{2 b}$ & 40 & $55 / 45$ & $12,10 \times 10^{-3} \pm 5,54 \times 10^{-4}$ \\
\hline $\mathbf{3}$ & 40 & $55 / 45$ & $13,99 \times 10^{-3} \pm 6,40 \times 10^{-4}$ \\
\hline
\end{tabular}

Comparing the experimental findings of three systems, the two endohedral fullerenes have the highest isomerization rates $\mathrm{K}_{\mathrm{H} 2 \mathrm{O} @ \mathrm{C} 60}>\mathrm{K}_{\mathrm{HF} @ \mathrm{C} 60}>\mathrm{K}_{\mathrm{C} 60}$ (see Table 1$)$. This confirms that the encapsulated molecule plays an important role in the zwitterionic intermediate stability. In view of the aforementioned results, the $\mathrm{H}$-bonding assistance is stronger for the $\mathrm{H}_{2} \mathrm{O} @ \mathrm{C}_{60}$ system according to the kinetic constants.

These experimental results are in good agreement with that predicted by theoretical calculations (see below).

\section{Mechanism for the enantiospecific cis/trans isomerization process.}

We have carried out density functional theory calculations at the M06-2X/6-311++G(d,p)//OLYP/TZP level of theory ${ }^{11}$ including solvent effects (acetonitrile) to analyze the cis-trans isomerization in the $\mathrm{HF} @ \mathrm{C}_{60}$ chiral fulleropyrrolidine $(2 S, 5 S)$-cis-2b (see S.I. for a detailed description of the computational methods). Nitrogen inversion in fulleropyrrolidines is fast ${ }^{12}$ and, consequently, we have done all our computations using the most stable conformation of the fulleropyrrolidine. Moreover, we have studied different orientations of the HF unit inside $\mathrm{C}_{60}$ for reactants, intermediates, and products and we have considered the most stable orientation in all cases (see S.I.).

Figure 5 provides the computed reaction path for the cis-trans isomerization and the retro-cycloaddition process for $(2 S, 5 S)$ cis-2b. For comparison purposes, it also includes the values for the analogous empty pyrrolidino[60]fullerene $(2 S, 5 S)$-cis- 2a and water-incarcerated endohedral fulleropyrrolidine $(2 S, 5 S)$-cis-3 taken from our previous study. ${ }^{8}$ As found in $\mathbf{2 a}$ and $\mathbf{3}$ and in agreement with experimental observations, PROD-(2S,5S)-cis-2b is more stable by $1.6 \mathrm{kcal} / \mathrm{mol}$ than PROD-(2S,5R)-trans-2b. This value is not far from the experimental $0.7 \mathrm{kcal} / \mathrm{mol}$ determined from the observed 77:23 ratio of products at $25{ }^{\circ} \mathrm{C}$. The cis-trans isomerization occurs through a stepwise mechanism with the formation of zwitterionic intermediates referred as INT- $(2 S, 5 S)$-cis-2b and INT$(2 S, 5 R)$-trans-2b in Figure 4. Zwitterionic intermediates of this type are not exceptional and, for instance, they were also found in 1,3-dipolar isomerizations on endohedral metallofullerenes. ${ }^{13}$ The heterolytic dissociation of the $\mathrm{C}-\mathrm{C}$ bond to form the zwitterionic intermediate is much easier at C5 (with an energy barrier less than $1 \mathrm{kcal} / \mathrm{mol}$ ) than at $\mathrm{C} 2$ position because of the electron withdrawing character of the carboxylic group (see Figure 2).;Error! Marcador no definido. This result explains the experimental observation that the $\mathrm{C} 2$ configuration is preserved along the whole isomerization process. After dissociation, the negative charge is located on the cage and the positive one in the benzylic cation. As compared to separated reactants, zwitterionic intermediates are about $1.5 \mathrm{kcal} / \mathrm{mol}$ more stable in $\mathrm{HF} @ \mathrm{C}_{60}$ than in hollow $\mathrm{C}_{60}$. The reason for this stabilization is the formation of an interaction between the $\mathrm{H}$ of the $\mathrm{HF}$ unit and the negatively charged $\mathrm{C}$ atom on the fullerene cage. The distance between the $\mathrm{H}$ atom of $\mathrm{HF}$ and $\mathrm{C} 5$ in the zwitterionic intermediate is ca. $2.6 \AA$ (see Figure 6). The $\mathrm{H}-\mathrm{F}$ distance in cis and trans intermediates is $0.931 \AA$, somewhat elongated as compared to that of $\mathrm{HF} @ \mathrm{C}_{60}(0.929 \AA)$, but less than that found in the hydrogen bonded $(\mathrm{HF})_{2}$ dimer $(0.937 \AA)$. Therefore, this $\mathrm{H} \cdots \mathrm{C}$ interaction in the zwitterionic intermediate can be classified as a weak hydrogen bond. Nevertheless, the higher stability of zwitterion INT- $(2 S, 5 S)$-cis-2b with respect to INT- $(2 S, 5 S)$ cis-3 (i.e. $1 \mathrm{kcal} / \mathrm{mol}$ ) is in line with the fact of $\mathrm{HF}$ being a better $\mathrm{H}$-bond acceptor than $\mathrm{H}_{2} \mathrm{O}$.

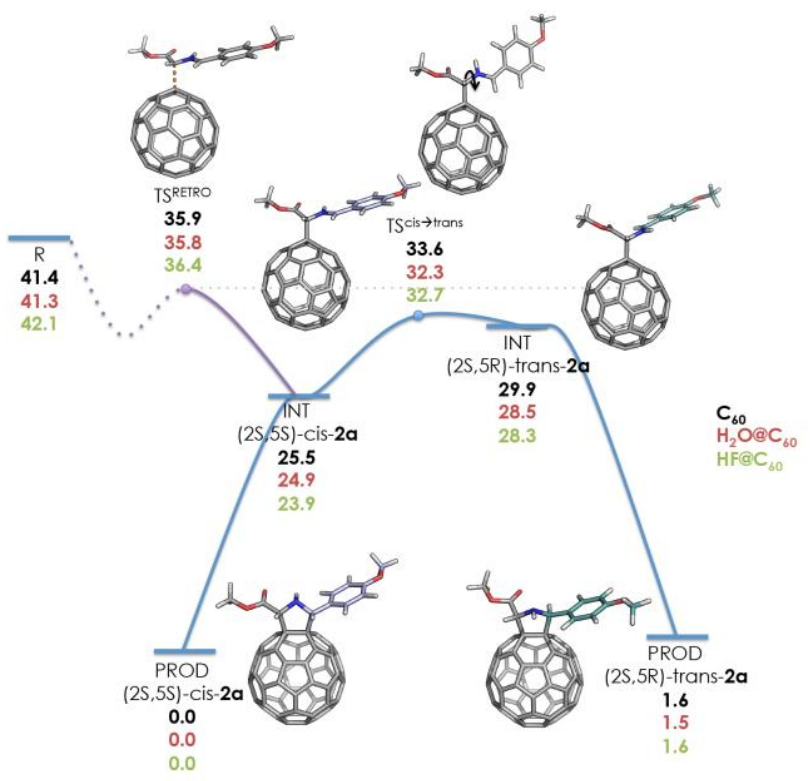

FIGURE 5. Relative M06-2X/6-311+G(d,p)//OLYP/TZP electronic energies for the cis-trans isomerization in $\mathbf{2 a}$ (black values), $\mathbf{3}$ (red values) and $\mathbf{2 b}$ (green values). The retro-Prato 
process is also included (in purple). All energies are in $\mathrm{kcal} / \mathrm{mol}$.

From the zwitterionic INT- $(2 S, 5 S)$-cis-2b, the system can evolve through two different pathways: i) cis-trans isomerization to produce INT-(2S,5R)-trans-2b or ii) retro-Prato reaction to recover the initial reactants. Isomerization occurs through rotation around the $\mathrm{C} 2-\mathrm{N}$ bond of INT- $(2 S, 5 S)$-cis$\mathbf{2 b}$ to yield INT-(2S,5R)-trans-2b, which evolves to PROD$(2 S, 5 R)$-trans-2b in an almost barrierless process. The retroPrato reaction from INT- $(2 S, 5 S)-c i s-2 \mathbf{b}$ is also possible, but it has a barrier that is about $3.7 \mathrm{kcal} / \mathrm{mol}$ higher than the cistrans isomerization process. This difference between the activation barrier for the retro-Prato and isomerization process is substantially larger in the case of $\mathrm{HF}$, as compared to free $\mathrm{C}_{60}$ and $\mathrm{H}_{2} \mathrm{O} @ \mathrm{C}_{60}$ (ca. 2.3 and $3.5 \mathrm{kcal} / \mathrm{mol}$, respectively). Therefore, especially in the case of $\mathrm{C}_{60}$, the retro-Prato pathway can compete with the isomerization process at high temperatures.

It is worth noting that the presence of the inner HF molecule does not affect the final relative stability of the cis and trans products. However, it has an important effect on the retro-reaction pathway and, especially, it has a significant influence on the energy barrier of the cis-trans isomerization process. The activation barrier is considerably lower in $\mathbf{2 b}$ (32.7 $\mathrm{kcal} / \mathrm{mol}$ with respect to the lowest energy cis product) as compared to $2 \mathrm{a}(33.6 \mathrm{kcal} / \mathrm{mol})$. This $c a$. $1 \mathrm{kcal} / \mathrm{mol}$ difference is in agreement with the improved stereochemical outcome observed experimentally for the HF@ $\mathrm{C}_{60}$ chiral fulleropyrrolidine. The encapsulated HF molecule assists the isomerization process by stabilizing the formed fullerene anion, where the hydrogen atom of HF is directly pointing to the negatively charged carbon atom on the fullerene surface. This distance is $c a$. $2.6 \AA$ in INT-(2S,5S)-cis-2b, and slightly longer in $\mathrm{TS}^{\text {cis } \rightarrow \text { trans }}(c a .2 .7 \AA$ ) (Figure 6), indicating that a small disruption of this $\mathrm{H}$-bond interaction occurs at the transition state. The slightly smaller energy barrier (by $0.4 \mathrm{kcal} / \mathrm{mol}$ ) for the cis-trans isomerization process in $\mathbf{3}$ as compared to $\mathbf{2} \mathbf{b}$ also concurs with the experimental rate constants (see Table 1). The latter may be due to the slightly weaker H-bond interaction between the carbon atom at the fullerene cage and the $\mathrm{H}_{2} \mathrm{O}$ molecule. This leads to a smaller energy penalty to achieve the $\mathrm{TS}^{\text {cis } \rightarrow \text { trans }}$ as compared to the HF case.

Our findings indicate the incarcerated HF molecule contributes to increase the isomerization rate without affecting the final cis-trans ratio or promoting the loss of enantioselective control through the retro-Prato reaction.

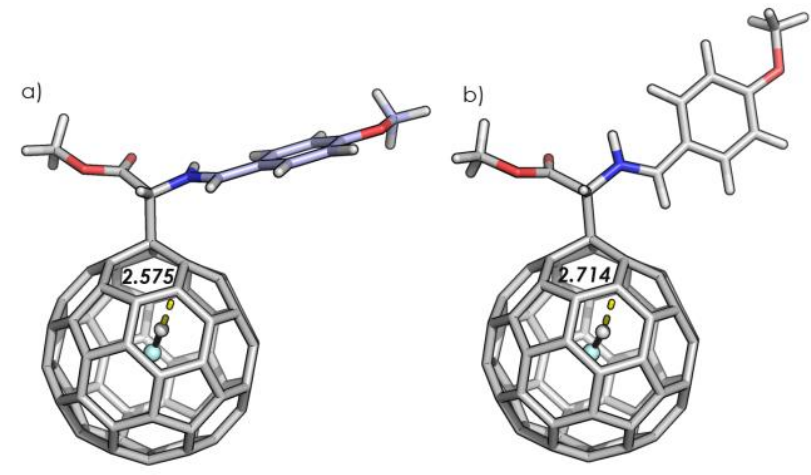

FIGURE 6. Optimized geometries at OLYP/TZP level of theory of a) INT- $(2 S, 5 S)-c i s-\mathbf{2 b}$ and b) TS ${ }^{\text {cis } \rightarrow \text { trans }}$ for $\mathrm{HF} @ \mathrm{C}_{60}$. Distances are in $\AA$.

\section{Conclusions}

In summary, we have carried out the first chemical modification on the recently reported $\mathrm{HF} @ \mathrm{C}_{60}$ endohedral by 1,3-dipolar cycloaddition on the fullerene cage. In this work, we have studied the isomerization process from the optically pure (2S,5S)-cis-pyrrolidino[60]fullerene $\mathbf{2 b}$ to the $(2 S, 5 R)$-transpyrrolidino[60]fullerene $\mathbf{2 b}$ and it has been compared with the empty $\mathrm{C}_{60}(\mathbf{2 a})$ and $\mathrm{H}_{2} \mathrm{O} @ \mathrm{C}_{60}(\mathbf{3})$ related fullerenes. This study has been carried out at moderate temperatures to avoid the competitive retro-cycloaddition process occurring at higher temperatures. It is worth mentioning that the easy availability of these optically active fullerenes enables the use of chiral information as a straightforward and powerful tool to shed light into the effect of the incarcerated molecule on the mechanism involved.

Interestingly, the incarcerated HF molecule contributes to increase the isomerization rate through a weak hydrogen bonding assistance without affecting the final cis-trans ratio or promoting the loss of enantioselective control through the retrocycloaddition reaction.

As a whole, the experimental findings reveal that the two endohedral fullerenes present the highest isomerization rates $\mathrm{H}_{2} \mathrm{O} @ \mathrm{C}_{60}>\mathrm{HF} @ \mathrm{C}_{60}>\mathrm{C}_{60}$, which confirms that the encapsulated molecule plays a significant role in the zwitterionic intermediate stability and, therefore, in the kinetics of the process. Actually, this first evidence of the assistance of the incarcerated $\mathrm{HF}$ molecule in the new $\mathrm{HF} @ \mathrm{C}_{60}$ paves the way to the study of a variety of reactions where the presence of the inner HF molecule can influence or determine the outcome of the chemical reactivity.

\section{ASSOCIATED CONTENT}

\section{Supporting Information}

General methods, synthesis of starting materials, spectroscopical data, computational methods, Relative stabilities of different HF orientations inside $\mathrm{C}_{60}$ for products and intermediates, and Cartesian coordinates of all stationary points located. The Supporting Information is available free of charge on the ACS Publications website. 


\section{AUTHOR INFORMATION}

\section{Corresponding Author}

- Nazario Martín: nazmar@ucm.es

- Richard J. Whitby: R.J.Whitby@ soton.ac.uk

- Miquel Solà: miquel.sola@udg.edu

\section{ACKNOWLEDGMENT}

This work was supported by the European Research Council ERC-320441-Chirallcarbon, Ministerio de Economía y Competitividad (MINECO) of Spain (project CTQ2014-52045-R) and the CAM (FOTOCARBON project S2013/MIT-2841). R.J.W. and S.A. thank the Engineering and Physical Sciences Research Council (UK) for funding this work (EP/1029451, M001962, M001970) including core capability (EP/K039466). M.I. thanks to Ministerio de Economía y Competitividad (MINECO) of Spain (Juan de la Cierva-Incorporación IJCI-2014-19320). We are also grateful for financial support from the Spanish MINECO (CTQ2014-54306-P, CTQ2014-59212-P, and RyC contract RYC-2014-16846 to S.O.), the Catalan DIUE (2014SGR931, ICREA Academia 2014 Award to M.S. and XRQTC), and the FEDER fund (UNGI10-4E-801). M.G.-B. thanks the Ramón Areces Foundation for a Postdoctoral Fellowship and S.O. the European Commission for CIG project (FP7-PEOPLE-2013-CIG630978), and the European Research Council (ERC) under the European Union's Horizon 2020 research and innovation program (ERC-2015-StG-679001). Excellent service from computational centers CSUC and BSC-CNS is acknowledged. NM thanks to EC FP7 ITN “MOLESCO” Project No. 606728.

\section{REFERENCES}

${ }^{1}$ Heath, J. R.; O'Brien, S. C.; Zhang, Q.; Liu, Y.; Curl, R. F.; Tittel, F. K.; Smalley, R. E. J. Am. Chem. Soc. 1985, 107, 7779-7780.

${ }^{2}$ a) Murata, Y.; Murata, M.; Komatsu, K. J. Am. Chem. Soc. 2003, 125, 7152-7153. b) Komatsu, K.; Murata, M.; Murata, Y.; Science, 2005, 307, 238-240.

${ }^{3}$ Morinaka, Y.; Tanabe, F.; Murata, M.; Murata, Y.; Komatsu, K. Chem. Commun. 2010, 46, 4532-4534.

${ }^{4}$ a) Kurotobi, K.; Murata, Y. Science, 2011, 333, 613-616. b) Hashikawa, Y.; Murata, M.; Wakamiya, A.; Murata, Y. Angew. Chem. Int. Ed. 2016, 55, 13109-13113.

${ }^{5}$ a) Feller D.; Peterson, K. A.; Theochem, 1997, 400, 69-70. b) Dolgonos, G. A.; Peslherbe, G. H. Phys. Chem. Chem. Phys. 2014, 16, 26294-26305.

${ }^{6}$ Krachmalnicoff, A.; Bounds, R.; Mamone, S.; Alom, S.; Concistrè, M.; Meier, B.; Kouřil, K.; Light, M. E.; Johnson, M. R.; Rols, S.; Horsewill, A. J.; Shugai, A.; Nagel, U.; Rõõm, T.; Carravetta, M.; Levitt M. H.; Whitby, R. J. Nat. Chem. 2016, 8, 953-957.

${ }^{7}$ a) Cerón, M. R.; Izquierdo, M.; Garcia-Borràs, M.; Lee, S. S.; Stevenson, S.; Osuna, S.; Echegoyen, L. J. Am. Chem. Soc. 2015, 137, 11775-11782. b) Yamada, M.; Wakahara, T.; Nakahodo, T.; Tsuchiya, T.; Maeda, Y.; Akasaka, T.; Yoza, K.; Horn, E.; Mizorogi, N.; Nagase, S. J. Am. Chem. Soc. 2006, 128, 1402-1403. c) Yamada, M.; Okamura, M.; Sato,
S.; Someya, C. I.; Mizorogi, N.; Tsuchiya, T.; Akasaka, T.; Kato, T.; Nagase, S. Chem. Eur. J. 2009, 15, 10533-10542. d) Izquierdo, M., Cerón, M. R., Olmstead, M. M., Balch, A. L.; Echegoyen, L. Angew. Chem. Int. Ed. 2013, 52, 11826-11830. e) Osuna, S.; Swart, M.; Solà, M. Phys. Chem. Chem. Phys. 2011, 13, 3585-3603. f) Garcia-Borràs, M.; Osuna, S.; Luis, J. M.; Swart, M.; Solà, M. Chem. Eur. J. 2013, 19, 1493114940.

${ }^{8}$ Maroto, E. E.; Mateos, J.; Garcia-Borràs, M.; Osuna, S.; Filippone, S.; Herranz, M. A.; Murata, Y.; Solà, M.; Martín, N. J. Am. Chem. Soc. 2015, 137, 1190-1197.

${ }^{9}$ a) Filippone, S.; Maroto, E. E.; Martín-Domenech, A.; Suárez, M.; Martín, N. Nat. Chem. 2009, 1, 578-582. b) Maroto, E. E.; de Cózar, A.; Filippone, S.; Martín-Domenech, Á.; Suárez, M.; Cossío, F. P.; Martín, N. Angew. Chem., Int. Ed. 2011, 50, 5974-6060. c) Maroto, E. E.; Filippone, S.; MartínDomenech, A.; Suárez, M.; Martín, N. J. Am. Chem. Soc. 2012, 134, 12936-12938. d) Maroto, E. E.; Filippone, S.; Suárez, M.; Martínez-Álvarez, R.; de Cózar, A.; Cossío, F. P.; Martín, N. J. Am. Chem. Soc. 2014, 136, 705-712. e) MarcoMartínez, J.; Marcos, V.; Reboredo, S.; Filippone, S.; Martín, N. Angew. Chem., Int. Ed. 2013, 52, 5115-5119. f) MarcoMartínez, J.; Reboredo, S.; Izquierdo, M.; Marcos, V.; López, J. L.; Filippone, S.; Martín, N. J. Am. Chem. Soc. 2014, 136, 2897-2904. g) Maroto, E. E.; Izquierdo, M.; Murata, M.; Filippone, S.; Komatsu, K.; Murata, Y.; Martín, N. Chem. Commun. 2014, 50, 740-742. h) Sawai, K.; Takano, Y.; Izquierdo, M.; Filipone, S.; Martín, N.; Slanina, Z.; Mizorogi, N.; Waelchli, M.; Tsuchiya, T.; Akasaka, T.; Nagase, S. J. Am. Chem. Soc. 2011, 133, 17746-17752. i) Maroto, E. E.; Marco-Martínez, J.; Izquierdo, M.; Reboredo, S.; Filippone S.; Martín, N. Acc. Chem. Res. 2014, 47, 2660-2670.

10 a) Filippone, S.; Izquierdo, M., Martín-Domenech, A.; Osuna, S.; Solà, M.; Martín, N. Chem. Eur. J., 2008, 14, 51985206. b) Martín, N.; Altable, M.; Filippone, S.; Martín-Domenech, A.; Echegoyen, L.; Cardona, C. M. Angew. Chem. Int. Ed. 2006, 45, 110-114. c) Lukoyanova, O.; Cardona, C. M.; Altable, M.; Filippone, S.; Martín, N.; Echegoyen, L. Angew. Chem. Int. Ed., 2006, 45, 7430-7433.

${ }^{11}$ a) Handy, N. C., Cohen. A. J. Mol. Phys. 2011, 99, 403-412. b) Lee, C.; Yang, W.; Parr, R. G. Phys. Rev. B 1992, 45, 13244- 13249. c) Baker, J.; Pulay, P. J. Chem. Phys. 2002, 117, 1441-1449. d) Zhao, Y.; Truhlar, D. G. Theor. Chem. Acc. 2008, 120, 215-241.

12 Lukoyanova, O.; Kitaygorodskiy, A.; Cardona, C. M.; Echegoyen, L. Chem. Eur. J. 2007, 13, 8294-8301.

13 Aroua, S.; Garcia-Borràs, M.; Osuna, S.; Yamakoshi, Y. Chem. Eur. J. 2014, 20, 14032-14039. 
${ }^{1}$ Heath, J. R.; O'Brien, S. C.; Zhang, Q.; Liu, Y.; Curl, R. F.; Tittel, F. K.; Smalley, R. E. J. Am. Chem. Soc. 1985, 107, 7779-7780.

${ }^{2}$ Y. Murata, M. Murata and K. Komatsu, J. Am. Chem. Soc. 2003, 125, 7152-7153.

${ }^{3}$ Morinaka, Y.; Tanabe, F.; Murata, M.; Murata, Y.; Komatsu, K. Chem. Commun. 2010, 46, 4532-4534.

${ }^{4}$ a) Kurotobi, K.; Murata, Y. Science, 2011, 333, 613-616. b) Hashikawa, Y.; Murata, M.; Wakamiya, A.; Murata, Y. Angew. Chem. Int. Ed. 2016, 55, 13109-13113.

${ }^{5}$ a) Feller D.; Peterson, K. A.; Theochem, 1997, 400, 69-70. b) Dolgonos, G. A.; Peslherbe, G. H. Phys. Chem. Chem. Phys. 2014, 16, 26294-26305.

${ }^{6}$ Krachmalnicoff, A.; Bounds, R.; Mamone, S.; Alom, S.; Concistrè, M.; Meier, B.; Kouřil, K.; Light, M. E.; Johnson, M. R.; Rols, S.; Horsewill, A. J.; Shugai, A.; Nagel, U.; Rõõm, T.; Carravetta, M.; Levitt M. H.; Whitby, R. J. Nat. Chem. 2016, 8, 953-957.

${ }^{7}$ a) Cerón, M. R.; Izquierdo, M.; Garcia-Borràs, M.; Lee, S. S.; Stevenson, S.; Osuna, S.; Echegoyen, L. J. Am. Chem. Soc. 2015, 137, 11775-11782. b) Yamada, M.; Wakahara, T.; Nakahodo, T.; Tsuchiya, T.; Maeda, Y.; Akasaka, T.; Yoza, K.; Horn, E.; Mizorogi, N.; Nagase, S. J. Am. Chem. Soc. 2006, 128, 1402-1403. c) Yamada, M.; Okamura, M.; Sato, S.; Someya, C. I.; Mizorogi, N.; Tsuchiya, T.; Akasaka, T.; Kato, T.; Nagase, S. Chem. Eur. J. 2009, 15, 10533-10542. d) Izquierdo, M., Cerón, M. R., Olmstead, M. M., Balch, A. L.; Echegoyen, L. Angew. Chem. Int. Ed. 2013, 52, 11826-11830. e) Osuna, S.; Swart, M.; Solà, M. Phys. Chem. Chem. Phys. 2011, 13, 3585-3603. f) Garcia-Borràs, M.; Osuna, S.; Luis, J. M.; Swart, M.; Solà, M. Chem. Eur. J. 2013, 19, 1493114940.

${ }^{8}$ Maroto, E. E.; Mateos, J.; Garcia-Borràs, M.; Osuna, S.; Filippone, S.; Herranz, M. A.; Murata, Y.; Solà, M.; Martín, N. J. Am. Chem. Soc. 2015, 137, 1190-1197.

${ }^{9}$ a) Filippone, S.; Maroto, E. E.; Martín-Domenech, A.; Suárez, M.; Martín, N. Nat. Chem. 2009, 1, 578-582. b) Maroto,
E. E.; de Cózar, A.; Filippone, S.; Martín-Domenech, Á.; Suárez, M.; Cossío, F. P.; Martín, N. Angew. Chem., Int. Ed. 2011, 50, 5974-6060. c) Maroto, E. E.; Filippone, S.; MartínDomenech, A.; Suárez, M.; Martín, N. J. Am. Chem. Soc. 2012, 134, 12936-12938. d) Maroto, E. E.; Filippone, S.; Suárez, M.; Martínez-Álvarez, R.; de Cózar, A.; Cossío, F. P.; Martín, N. J. Am. Chem. Soc. 2014, 136, 705-712. e) MarcoMartínez, J.; Marcos, V.; Reboredo, S.; Filippone, S.; Martín, N. Angew. Chem., Int. Ed. 2013, 52, 5115-5119. f) MarcoMartínez, J.; Reboredo, S.; Izquierdo, M.; Marcos, V.; López, J. L.; Filippone, S.; Martín, N. J. Am. Chem. Soc. 2014, 136, 2897-2904. g) Maroto, E. E.; Izquierdo, M.; Murata, M.; Filippone, S.; Komatsu, K.; Murata, Y.; Martín, N. Chem. Commun. 2014, 50, 740-742. h) Sawai, K.; Takano, Y.; Izquierdo, M.; Filipone, S.; Martín, N.; Slanina, Z.; Mizorogi, N.; Waelchli, M.; Tsuchiya, T.; Akasaka, T.; Nagase, S. J. Am. Chem. Soc. 2011, 133, 17746-17752. i) Maroto, E. E.; Marco-Martínez, J.; Izquierdo, M.; Reboredo, S.; Filippone S.; Martín, N. Acc. Chem. Res. 2014, 47, 2660-2670.

${ }^{10}$ Filippone, S.; Izquierdo, M., Martín-Domenech, A.; Osuna, S.; Solà, M.; Martín, N. Chem. Eur. J., 2008, 14, 5198-5206. b) Martín, N.; Altable, M.; Filippone, S.; Martín-Domenech, A.; Echegoyen, L.; Cardona, C. M. Angew. Chem. Int. Ed. 2006, 45, 110-114.

${ }^{11}$ a) Handy, N. C., Cohen. A. J. Mol. Phys. 2011, 99, 403-412. b) Lee, C.; Yang, W.; Parr, R. G. Phys. Rev. B 1992, 45, 13244- 13249. c) Baker, J.; Pulay, P. J. Chem. Phys. 2002, 117, 1441-1449. d) Zhao, Y.; Truhlar, D. G. Theor. Chem. Acc. 2008, 120, 215-241.

${ }^{12}$ Lukoyanova, O.; Kitaygorodskiy, A.; Cardona, C. M.; Echegoyen, L. Chem. Eur. J. 2007, 13, 8294-8301.

${ }^{13}$ Aroua, S.; Garcia-Borràs, M.; Osuna, S.; Yamakoshi, Y. Chem. Eur. J. 2014, 20, 14032-14039. 